\title{
Waist circumference and waist-to-height ratio in Han Chinese children living in Chongqing, south-west China
}

\author{
Feng Xiong ${ }^{1}$, Sarah P Garnett ${ }^{2,3, *}$, Chris T Cowell ${ }^{2,3}$, Cornelis Biesheuvel ${ }^{3,4}$, \\ Yan Zeng', Chun-Li Long', Qing Wang', Dong-Gang Wang', Yan-Hong Luo' ${ }^{1}$ and \\ Shun-Qing Luo' \\ 'Endocrinology Department, Children's Hospital, Chongqing Medical University, Chongqing, People's Republic of \\ China: ${ }^{2}$ Institute of Endocrinology and Diabetes, The Children's Hospital at Westmead, Locked Bag 4001, \\ Westmead, NSW 2145, Australia: ${ }^{3}$ The Kids Research Institute, The Children's Hospital at Westmead, Westmead, \\ NSW, Australia: ${ }^{4}$ Karolinska Institute, Department of Medical Epidemiology and Biostatistics, Stockholm, Sweden
}

Submitted 25 August 2009: Accepted 20 January 2010: First published online 18 March 2010

\begin{abstract}
Objective: To derive age- and sex-specific reference values for waist circumference (WC) and waist-to-height ratio (WHtR) for Han Chinese children and adolescents and to establish the prevalence of excess central adiposity in our study population. Design: Cross-sectional study of schoolchildren attending randomly selected primary and secondary schools in south-west China in October 2003 and April 2004. Anthropometry was measured using standard procedures. The LMS method was used to construct smoothed WC and WHtR percentile curves. Overweight and obesity were defined by the International Obesity Task Force (IOTF) criteria and the Working Group on Obesity in Children. Excess central adiposity fat was defined by previously published WC cut-points and a WHtR $\geq 0 \cdot 5$.

Setting: Primary and secondary schools in Chongqing, south-west China.

Subjects: A total of $7326(49 \cdot 2 \%$ boys) Han Chinese students at 5-17 years old.

Results: On the basis of the IOTF criteria, $26.4 \%$ of boys were overweight or obese compared with $16 \cdot 4 \%$ of girls $(P<0 \cdot 001)$. WC cut-points identified $31 \%$ of boys and $28 \%$ of girls as having excess central adiposity, whereas using the WHtR criterion, $14 \cdot 8 \%$ of boys and $5 \cdot 6 \%$ of girls were identified. Young boys (5-12 years) had a significantly $(P<0 \cdot 001)$ higher WHtR than girls.

Conclusions: We have constructed WC and WHtR percentile curves for Han Chinese children and adolescents living in Chongqing. Our measurements were based on a student population with a relatively high rate of overweight and obesity. These data will provide a point of reference for future studies measuring the prevalence of overweight and obesity in China.
\end{abstract}

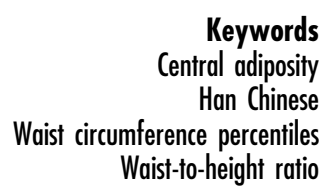

Over the past two decades the prevalence of childhood overweight and obesity has increased dramatically in large Chinese cities ${ }^{(1)}$. In parallel, there has been an escalated incidence of the metabolic syndrome ${ }^{(2)}$, a clustering of cardiovascular risk factors including dyslipidaemia, hypertension and insulin resistance ${ }^{(3)}$. Excessive accumulation of adipose tissue in both central subcutaneous and visceral regions of children and adolescents has been associated with these metabolic abnormalities ${ }^{(4)}$. The recommended anthropometric measures that reflect central adiposity distribution in children include waist circumference (WC) and waist-to-height ratio (WHtR). Both measures are highly sensitive to upper body fat accumulation and predict adverse cardiovascular risk factors ${ }^{(5,6)}$.

Several studies have described ethnic differences in $\mathrm{WC}^{(7-10)}$ and there are recognised cut-points for WC for both European and Asian adults ${ }^{(11)}$. For children and adolescents, WC cut-points tend to be based on age- and sex-specific reference values. Age- and sex-related WC percentile values have been established in several countries including the United States, the United Kingdom and Australia ${ }^{(7,10,12)}$. WC percentile charts have been developed for children living in Hong Kong ${ }^{(13)}$ and Xinjiang Uygur Autonomous Region ${ }^{(14)}$, in north-west China. However, both percentile charts have limitations. The percentile charts for Hong Kong children do not differentiate between ethnicities and the Xinjiang autonomous region charts are based on limited numbers of children in each age group (median: seventy-nine; (range: forty-seven to 131)).

The WHtR has also been proposed as a measure of central adiposity and studies in adults and children have suggested a cut-point of 0.5 as a simple means of indicating 
whether the amount of central fat is excessive ${ }^{(5,15)}$. The WHtR cut-point has several advantages over WC cutpoints as it is easy to calculate and it is not age and sex specific. WHtR has not been previously described in Han Chinese children.

Establishing normative ethnic-specific data are essential for early detection of excess central adiposity. The aim of the present study was to derive age- and sex-specific reference values for WC and WHtR in Han Chinese children and adolescents and to establish the prevalence of excess central adiposity in our study population.

\section{Materials and methods}

\section{Participants}

This is a school based, cross-sectional study that was conducted in the city of Chongqing, south-west China in October 2003 (primary schools) and in April 2004 (secondary schools). The total city population is approximately thirty-two million of which $4 \cdot 4$ million are primary- and secondary-school students (National Chinese Census 2006, personal communication (F.X.) with the Office of Primary and Middle School Health of Chongqing Education Committee). For the present study, 7326 ( $49 \cdot 2 \%$ boys) Han Chinese students aged 5-17 years were recruited from fifteen primary schools and nine secondary schools from a potential of thirty-eight primary schools and eighteen secondary schools in Chongqing. School selection was undertaken by the Office of Primary and Middle School Health of Chongqing Education Committee and was based on randomly computer-generated numbering to represent both urban and city areas and to be representative of total school community. Two classes in each grade were selected in collaboration with the school principal based on timetables and operational needs. A written informed consent was obtained from $\sim 99 \%$ of the participants or from their parents and the research protocol was approved by the Primary and Secondary School Physical Health Division of the Chongqing Education Committee.

\section{Measurements}

Anthropometric measurements included height, weight and WC. Height was measured without shoes to the nearest $0.5 \mathrm{~cm}$ by a standard stadiometer. Weight was measured to the nearest $0.5 \mathrm{~kg}$ on calibrated scales, wearing light clothing. WC was measured midway between the lowest rib and the superior border of the iliac crest with a non-elastic flexible tape and was recorded to the nearest centimetre. All anthropometric measurements were performed by trained health technicians. BMI was calculated as weight $/$ height ${ }^{2}\left(\mathrm{~kg} / \mathrm{m}^{2}\right)$ and WHtR by dividing the WC $(\mathrm{cm})$ by height $(\mathrm{cm})$. Overweight and obesity were defined by age- and sex-specific BMI cut-off points according to the International Obesity Task
Force (IOTF) criteria $^{(16)}$ and Working Group on Obesity in Children (WGOC) ${ }^{(17)}$ for children aged 7 years and older. Excess central fat was defined by previously published WC standards based on ethnic Chinese living in Hong Kong ${ }^{(18,19)}$ and a WHtR $\geq 0 \cdot 5^{(15)}$.

\section{Statistical analysis}

Data were analysed using the Statistical Package for the Social Sciences statistical software package version $15 \cdot 0$ for Windows (SPSS Inc., Chicago, IL, USA). After assessing the data distribution, sex differences in anthropometric data were assessed with the Student's $t$ test. Association between age and WHtR was assessed using curve estimation. The $\chi^{2}$ test was used as a measure of association between categorical variables. The LMS method ${ }^{(20)}$ was used to construct smoothed percentile curves for WC using LMS ChartMaker Light ${ }^{(21)}$. The LMS method summarises the changing distribution by three curves representing the median (M), coefficient of variation (S) and skewness (L); the latter expressed as a Box-Cox power. Using penalised likelihood methods, the three curves are fitted as cubic splines by nonlinear regression, and the extent of smoothing required is expressed in terms of smoothing parameters or equivalent degrees of freedom. Agreement between criteria for classifying overweight and obesity was assessed by the $\kappa$ statistic.

\section{Results}

The anthropometric characteristics of the study population are shown in Table 1. Boys were generally taller than girls, except at 10 years of age when girls were on average $2.9 \mathrm{~cm}$ taller than boys $(P<0 \cdot 001)$. Boys aged $6-10$ years also had a significantly higher BMI $(P<0 \cdot 001)$. However, after the age of 10 years sex difference in anthropometry were small. Overall, using IOTF criteria $26.4 \%$ of boys were overweight or obese compared with $16.4 \%$ of girls $(P<0 \cdot 001)$ and using the WGOC criteria (for children $\geq 7$ years) $29 \cdot 7 \%$ of boys and $19.4 \%$ of girls $(P<0.001)$ were overweight or obese. The two classification criteria showed very good agreement ( $\kappa=0 \cdot 88, P<0 \cdot 001) ; 99 \cdot 6 \%$ of children defined as overweight or obese using the IOTF criteria were also defined as overweight and obese using the WGOC criteria.

Smoothed WC and WHtR percentile curves for boys and girls are shown in Figs 1 and 2. The percentile values are shown in Tables 2 and 3 (WC and WHtR). WC increased with age in both sexes until 15 years and then plateaued. Boys had a higher WC than girls. The mean WHtR was also higher in boys than girls until the age of 12 years $(P<0 \cdot 001)$. In adolescents, the only statistical difference that was observed between sexes was at 15 years when girls had a higher WHtR than boys, 0.43 compared with $0.42(P<0 \cdot 001)$. In contrast to the association between age and $\mathrm{WC}$, the association between age and WHtR was flatter. In boys this association was negative, age explaining $2.5 \%$ of the variance $\left(R^{2}=-0.025\right.$, 
Table 1 Anthropometric measures, prevalence of overweight and obesity, and excess central adiposity

\begin{tabular}{|c|c|c|c|c|c|c|c|c|c|c|c|c|c|c|c|}
\hline \multirow[b]{2}{*}{ Age (years) $\dagger$} & \multirow[b]{2}{*}{$n$} & \multicolumn{2}{|c|}{ Height $(\mathrm{cm})$} & \multicolumn{2}{|c|}{ Weight (kg) } & \multicolumn{2}{|c|}{ BMI $\left(\mathrm{kg} / \mathrm{m}^{2}\right)$} & \multicolumn{2}{|c|}{ Overweight } & \multicolumn{2}{|c|}{ Obese } & \multicolumn{2}{|c|}{ Excess central adiposity $(\mathrm{WC})^{*}$} & \multicolumn{2}{|c|}{ Excess central adiposity $(\mathrm{WHtR} \geq 0.5)$} \\
\hline & & Mean & SD & Mean & SD & Mean & SD & $n$ & $\%$ & $n$ & $\%$ & $n$ & $\%$ & $n$ & $\%$ \\
\hline \multicolumn{16}{|l|}{ Boys } \\
\hline 5 & 96 & $122 \cdot 1$ & $5 \cdot 2$ & $25 \cdot 7$ & $4 \cdot 5$ & $17 \cdot 1$ & $2 \cdot 1$ & 17 & $17 \cdot 7$ & 10 & $10 \cdot 4$ & $-\ddagger$ & & 13 & $13 \cdot 5$ \\
\hline 6 & 217 & $125 \cdot 7$ & $5 \cdot 6$ & $27 \cdot 7$ & $4 \cdot 1$ & $17 \cdot 4$ & $2 \cdot 2$ & 61 & $28 \cdot 1$ & 21 & $9 \cdot 7$ & 92 & $42 \cdot 4$ & 42 & $19 \cdot 4$ \\
\hline 7 & 231 & $130 \cdot 1$ & $6 \cdot 7$ & $30 \cdot 2$ & $6 \cdot 3$ & $17 \cdot 7$ & $2 \cdot 6$ & 59 & $25 \cdot 5$ & 21 & $9 \cdot 1$ & 104 & $45 \cdot 0$ & 39 & $16 \cdot 9$ \\
\hline 8 & 311 & $132 \cdot 2$ & 8.9 & $31 \cdot 2$ & $7 \cdot 6$ & $17 \cdot 6$ & $2 \cdot 6$ & 65 & $20 \cdot 9$ & 21 & $6 \cdot 8$ & 102 & $32 \cdot 8$ & 49 & $15 \cdot 8$ \\
\hline 9 & 342 & $136 \cdot 2$ & $10 \cdot 2$ & $34 \cdot 3$ & $9 \cdot 7$ & $18 \cdot 1$ & $3 \cdot 1$ & 70 & $20 \cdot 5$ & 28 & $8 \cdot 2$ & 113 & 33.0 & 59 & $17 \cdot 3$ \\
\hline 10 & 328 & $141 \cdot 3$ & $10 \cdot 0$ & $38 \cdot 1$ & $10 \cdot 5$ & $18 \cdot 8$ & $3 \cdot 1$ & 76 & $23 \cdot 2$ & 23 & $7 \cdot 0$ & 107 & $32 \cdot 6$ & 60 & $18 \cdot 3$ \\
\hline 11 & 347 & $149 \cdot 3$ & $10 \cdot 9$ & $43 \cdot 3$ & $11 \cdot 0$ & $19 \cdot 2$ & 3.0 & 73 & $21 \cdot 0$ & 14 & $4 \cdot 0$ & 103 & $29 \cdot 7$ & 49 & $14 \cdot 1$ \\
\hline 12 & 353 & $155 \cdot 3$ & 11.9 & $48 \cdot 9$ & $14 \cdot 0$ & $19 \cdot 9$ & $3 \cdot 8$ & 71 & $20 \cdot 1$ & 22 & $6 \cdot 2$ & 105 & $29 \cdot 7$ & 56 & $15 \cdot 9$ \\
\hline 13 & 352 & $160 \cdot 4$ & $11 \cdot 3$ & $52 \cdot 2$ & $13 \cdot 6$ & $20 \cdot 0$ & 3.6 & 54 & $15 \cdot 3$ & 16 & $4 \cdot 5$ & 79 & $22 \cdot 4$ & 35 & 9.9 \\
\hline 14 & 274 & $166 \cdot 7$ & 8.5 & $60 \cdot 1$ & $13 \cdot 4$ & $21 \cdot 5$ & 3.9 & 53 & $19 \cdot 3$ & 25 & $9 \cdot 1$ & 88 & $32 \cdot 1$ & 46 & $16 \cdot 8$ \\
\hline 15 & 295 & $170 \cdot 6$ & $6 \cdot 0$ & $63 \cdot 1$ & $11 \cdot 6$ & $21 \cdot 6$ & $3 \cdot 6$ & 54 & $18 \cdot 3$ & 14 & $4 \cdot 7$ & 91 & $30 \cdot 9$ & 31 & $10 \cdot 5$ \\
\hline 16 & 319 & $170 \cdot 7$ & $5 \cdot 9$ & $63 \cdot 4$ & $11 \cdot 7$ & $21 \cdot 7$ & $3 \cdot 6$ & 39 & $12 \cdot 2$ & 15 & $4 \cdot 7$ & 90 & $28 \cdot 2$ & 35 & $11 \cdot 0$ \\
\hline 17 & 136 & $172 \cdot 1$ & $5 \cdot 8$ & $64 \cdot 7$ & $11 \cdot 2$ & $21 \cdot 8$ & 3.5 & 23 & $16 \cdot 9$ & 6 & $4 \cdot 4$ & 37 & $27 \cdot 2$ & 17 & 12.5 \\
\hline Total & 3603 & $150 \cdot 0$ & $18 \cdot 5$ & $45 \cdot 6$ & $17 \cdot 0$ & $19 \cdot 51$ & $3 \cdot 6$ & 715 & $19 \cdot 9$ & 236 & $6 \cdot 6$ & 1112 & $30 \cdot 9$ & 531 & $14 \cdot 7$ \\
\hline \multicolumn{16}{|l|}{ Girls } \\
\hline 5 & 147 & $120 \cdot 4$ & $4 \cdot 8$ & $24 \cdot 4$ & $3 \cdot 5$ & $16 \cdot 8$ & 1.9 & 35 & $23 \cdot 8$ & 11 & $7 \cdot 5$ & $-\ddagger$ & & 10 & $6 \cdot 8$ \\
\hline 6 & 226 & $123 \cdot 4$ & $5 \cdot 3$ & $25 \cdot 3$ & $3 \cdot 4$ & $16 \cdot 5$ & 1.5 & 47 & $20 \cdot 8$ & 5 & $2 \cdot 2$ & 55 & $24 \cdot 3$ & 9 & $4 \cdot 0$ \\
\hline 7 & 254 & $128 \cdot 3$ & $7 \cdot 5$ & $28 \cdot 0$ & $5 \cdot 7$ & $16 \cdot 9$ & $2 \cdot 2$ & 41 & $16 \cdot 1$ & 10 & 3.9 & 68 & $26 \cdot 8$ & 15 & 5.9 \\
\hline 8 & 296 & $131 \cdot 1$ & $9 \cdot 2$ & $29 \cdot 6$ & $7 \cdot 0$ & $17 \cdot 0$ & $2 \cdot 3$ & 40 & $13 \cdot 5$ & 13 & $4 \cdot 4$ & 64 & $21 \cdot 6$ & 16 & $5 \cdot 4$ \\
\hline 9 & 312 & $136 \cdot 1$ & $9 . \overline{9}$ & 32.5 & 8.5 & $17 \cdot 3$ & $2 \cdot 8$ & 40 & $12 \cdot 8$ & 9 & $2 \cdot 9$ & 67 & 21.5 & 17 & $5 \cdot 5$ \\
\hline 10 & 299 & $144 \cdot 2$ & $9 \cdot 9$ & $37 \cdot 6$ & $9 \cdot 2$ & $17 \cdot 9$ & $2 \cdot 8$ & 42 & $14 \cdot 0$ & 7 & $2 \cdot 3$ & 74 & $42 \cdot 7$ & 7 & $2 \cdot 3$ \\
\hline 11 & 359 & $149 \cdot 2$ & $9 \cdot 1$ & $42 \cdot 3$ & $9 \cdot 7$ & $18 \cdot 8$ & $2 \cdot 8$ & 55 & $15 \cdot 3$ & 4 & $1 \cdot 1$ & 78 & $21 \cdot 7$ & 14 & 3.9 \\
\hline 12 & 351 & $152 \cdot 0$ & $8 \cdot 4$ & $45 \cdot 7$ & $10 \cdot 0$ & $19 \cdot 6$ & $3 \cdot 1$ & 58 & $16 \cdot 5$ & 6 & $1 \cdot 7$ & 94 & $26 \cdot 8$ & 26 & $7 \cdot 4$ \\
\hline 13 & 433 & $156 \cdot 0$ & $7 \cdot 4$ & $49 \cdot 8$ & $10 \cdot 0$ & $20 \cdot 4$ & $3 \cdot 4$ & 59 & $13 \cdot 6$ & 12 & $2 \cdot 8$ & 116 & $26 \cdot 8$ & 25 & $5 \cdot 8$ \\
\hline 14 & 336 & $158 \cdot 2$ & $6 \cdot 1$ & $52 \cdot 9$ & $8 \cdot 1$ & $21 \cdot 1$ & $2 \cdot 7$ & 42 & $12 \cdot 5$ & 4 & $1 \cdot 2$ & 137 & $40 \cdot 8$ & 26 & $7 \cdot 7$ \\
\hline 15 & 313 & 158.7 & 5.9 & $53 \cdot 1$ & $7 \cdot 5$ & $21 \cdot 1$ & $2 \cdot 5$ & 32 & $10 \cdot 2$ & 2 & $0 . \overline{6}$ & 121 & $38 \cdot 7$ & 23 & $7 \cdot 3$ \\
\hline 16 & 284 & $159 \cdot 9$ & $5 \cdot 2$ & $53 \cdot 4$ & $7 \cdot 3$ & $20 \cdot 9$ & $2 \cdot 5$ & 25 & $8 \cdot 8$ & 1 & 0.4 & 104 & $36 \cdot 6$ & 15 & $5 \cdot 3$ \\
\hline 17 & 113 & $159 \cdot 7$ & $5 \cdot 2$ & $54 \cdot 4$ & $7 \cdot 1$ & $21 \cdot 3$ & $5 \cdot 3$ & 12 & $10 \cdot 6$ & 0 & 0.0 & 35 & $31 \cdot 0$ & 5 & $4 \cdot 4$ \\
\hline Total & 3723 & $145 \cdot 9$ & $15 \cdot 1$ & $41 \cdot 6$ & $13 \cdot 2$ & $19 \cdot 0$ & $3 \cdot 2$ & 528 & $14 \cdot 2$ & 84 & $2 \cdot 3$ & 1013 & $27 \cdot 2$ & 208 & $5 \cdot 6$ \\
\hline
\end{tabular}

WC, waist circumference; WHtR, waist-to-height ratio.

"Age- and sex-specific cut-points based on ethnic Chinese children living in Hong Kong ${ }^{(18,19)}$.

tAge is in whole years, e.g. 5 years $=5-5.99$ years.

$\ddagger$ No cut-point available for 5 -year-old children. 

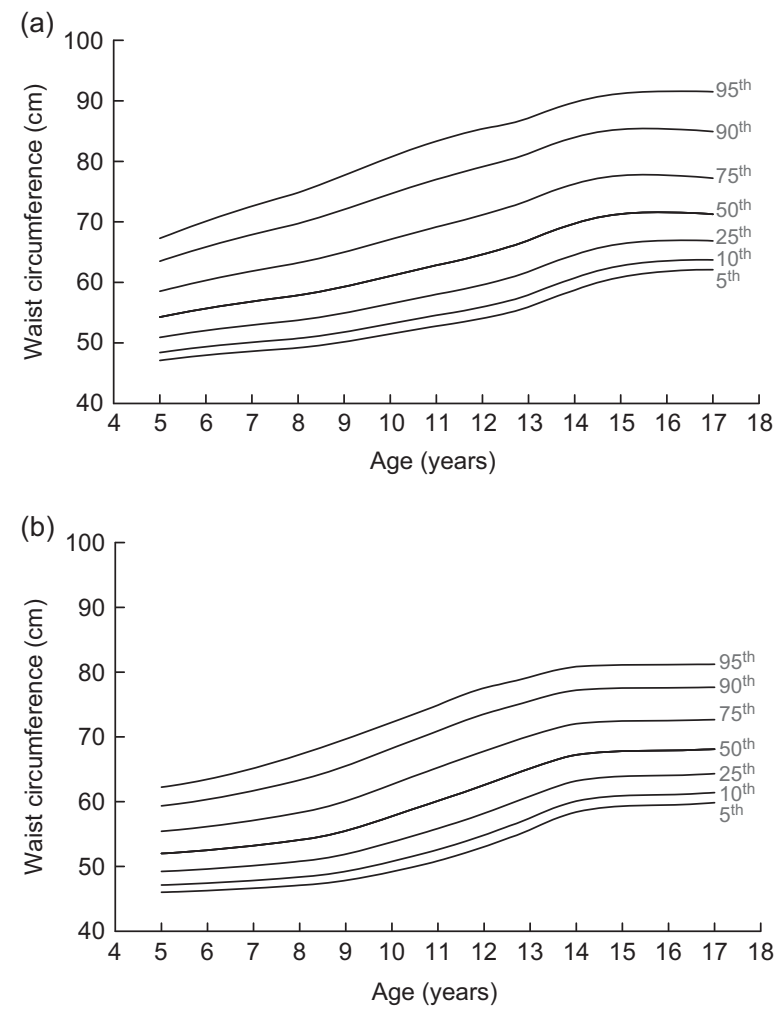

Fig. 1 Smoothed waist circumference curves for the 5th, 10th, 25th, 50th, 75th, 90th and 95th percentile for (a) boys and (b) girls

$P<0 \cdot 001)$. The relation between age and WHtR in girls was best described as quadratic $\left(R^{2}=0 \cdot 021, P<0 \cdot 001\right.$; Fig. 2).

The age- and sex-specific WC cut-points based on ethnic Chinese living in Hong Kong were approximately equivalent to the 70 th percentile of our population; $31.7 \%$ of boys and $28.3 \%$ of girls were identified as having excess central adiposity (Table 1). Using these WC cutpoints, excess central adiposity was particularly prevalent in 6- and 7-year-old boys (43.8\%) and 14- to 17-year-old girls $(36 \cdot 8 \%)$. In comparison the WHtR cut-point of 0.5 identified $14 \cdot 8 \%$ of boys and $10 \cdot 8 \%$ of girls as having excess central adiposity (Table 1 ). The highest WHtR was observed $(0 \cdot 71)$ in a 14-year-old boy who had a BMI of $37 \cdot 4 \mathrm{~kg} / \mathrm{m}^{2}, 2 \cdot 3 \%$ of children $(3 \cdot 1 \%$ boys, $1 \cdot 1 \%$ girls $)$ had a WHtR $>0.55$ and $0.7 \%(1.1 \%$ boys, $0.3 \%$ girls $)$ had a WHtR $>0 \cdot 6$.

\section{Discussion}

We constructed WC and WHtR percentiles for Han Chinese children, aged 5 to 17 years, living in the city of Chongqing in 2003 and 2004. Our WC percentiles are similar to those published on Han Chinese children living in Xingjiang Uyger Autonomous Region ${ }^{(14)}$ but higher than those published on children living in Hong Kong in
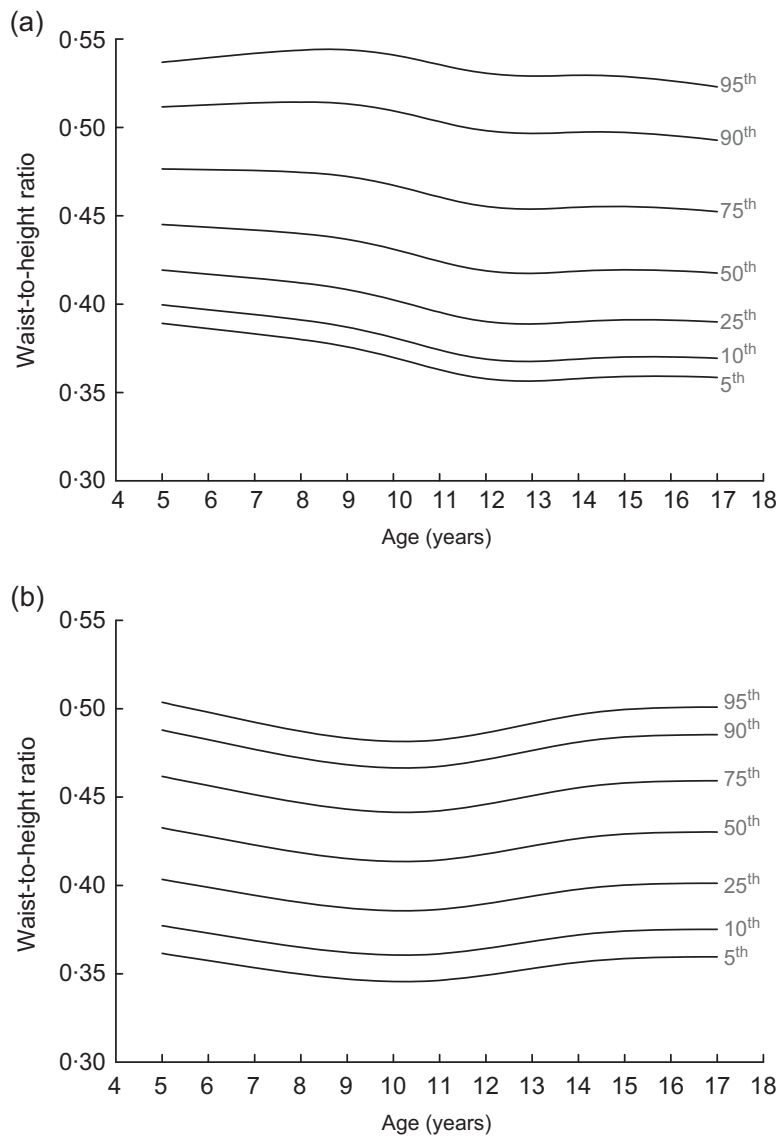

Fig. 2 Smoothed waist-to-height ratio curves for the 5th, 10th, 25th, 50th, 75th, 90th and 95th percentile for (a) boys and (b) girls

2005 and 2006 (Table 4) ${ }^{(13)}$. At the 90th percentile the differences ranged from 2.4 to $7.2 \mathrm{~cm}$ in boys and from 1.8 to $6.9 \mathrm{~cm}$ in girls and were greater in both sexes during early adolescence (13-15 years) compared with younger children (6-9 years).

The difference in WC between Han Chinese living in China and children living in Hong Kong can be explained, in part, by the different rates of overweight and obesity as defined by the IOTF criteria. In our cohort, $26 \%$ of boys and $16 \%$ of girls were overweight or obese compared with $21 \%$ and $14 \%$ of boys and girls in the Hong Kong cohort. Similar rates of overweight and obesity to ours have been reported in Han adolescents (12-14 years old) living in Beijing; $24 \%$ of boys and $18 \%$ of girls were overweight or obese ${ }^{(2)}$. These rates are considerably higher than the 2002 Chinese national figures of $6 \%$ for children aged $7-17$ years ${ }^{(22)}$. The disparity between different rates of overweight and obesity in rural China and large cities has been well documented $^{(22)}$. The WC percentile data in our study population are likely to represent the current trend in overweight and obesity in Chinese cities.

Ethnicity is also a potential confounder in explaining the difference in WC and WHtR percentiles. It is estimated 
Table 2 Waist circumference $(\mathrm{cm})$ percentiles for boys and girls

\begin{tabular}{rrrrrrrrr}
\hline Age (years) $^{*}$ & $n$ & 5 th & 10 th & 25 th & 50 th & 75 th & 90 th & 95 th \\
\hline Boys & & & & & & & & \\
5 & 96 & $47 \cdot 1$ & $48 \cdot 4$ & $50 \cdot 9$ & $54 \cdot 3$ & $58 \cdot 5$ & $63 \cdot 5$ & $67 \cdot 3$ \\
6 & 217 & $48 \cdot 0$ & $49 \cdot 4$ & $52 \cdot 0$ & $55 \cdot 7$ & $60 \cdot 3$ & $65 \cdot 8$ & $70 \cdot 1$ \\
7 & 231 & $48 \cdot 7$ & $50 \cdot 1$ & $53 \cdot 0$ & $56 \cdot 9$ & $61 \cdot 9$ & $67 \cdot 9$ & $72 \cdot 6$ \\
8 & 311 & $49 \cdot 2$ & $50 \cdot 8$ & $53 \cdot 8$ & $57 \cdot 9$ & $63 \cdot 2$ & $69 \cdot 7$ & $74 \cdot 8$ \\
9 & 342 & $50 \cdot 2$ & $51 \cdot 8$ & $54 \cdot 9$ & $59 \cdot 3$ & $65 \cdot 0$ & $72 \cdot 0$ & $77 \cdot 7$ \\
10 & 328 & $51 \cdot 5$ & $53 \cdot 2$ & $56 \cdot 5$ & $61 \cdot 0$ & $67 \cdot 1$ & $74 \cdot 6$ & $80 \cdot 7$ \\
11 & 347 & $52 \cdot 8$ & $54 \cdot 6$ & $58 \cdot 0$ & $62 \cdot 8$ & $69 \cdot 2$ & $77 \cdot 0$ & $83 \cdot 3$ \\
12 & 353 & $54 \cdot 1$ & $56 \cdot 0$ & $59 \cdot 6$ & $64 \cdot 6$ & $71 \cdot 2$ & $79 \cdot 1$ & $85 \cdot 4$ \\
13 & 352 & $55 \cdot 9$ & $57 \cdot 9$ & $61 \cdot 7$ & $66 \cdot 9$ & $73 \cdot 5$ & $81 \cdot 2$ & $87 \cdot 1$ \\
14 & 274 & $58 \cdot 7$ & $60 \cdot 7$ & $64 \cdot 5$ & $69 \cdot 7$ & $76 \cdot 3$ & $84 \cdot 0$ & $89 \cdot 8$ \\
15 & 295 & $60 \cdot 9$ & $62 \cdot 8$ & $66 \cdot 4$ & $71 \cdot 3$ & $77 \cdot 7$ & $85 \cdot 3$ & $91 \cdot 2$ \\
16 & 319 & $61 \cdot 8$ & $63 \cdot 6$ & $66 \cdot 9$ & $71 \cdot 6$ & $77 \cdot 7$ & $85 \cdot 4$ & $91 \cdot 6$ \\
17 & 136 & $62 \cdot 1$ & $63 \cdot 7$ & $66 \cdot 9$ & $71 \cdot 3$ & $77 \cdot 2$ & $84 \cdot 9$ & $91 \cdot 5$ \\
Girls & & & & & & & & \\
5 & 147 & $46 \cdot 2$ & $47 \cdot 3$ & $49 \cdot 3$ & $51 \cdot 9$ & $55 \cdot 1$ & $58 \cdot 8$ & $61 \cdot 5$ \\
6 & 226 & $46 \cdot 2$ & $47 \cdot 4$ & $49 \cdot 6$ & $52 \cdot 5$ & $56 \cdot 1$ & $60 \cdot 2$ & $63 \cdot 3$ \\
7 & 254 & $46 \cdot 5$ & $47 \cdot 8$ & $50 \cdot 1$ & $53 \cdot 3$ & $57 \cdot 3$ & $62 \cdot 0$ & $65 \cdot 6$ \\
8 & 296 & $47 \cdot 0$ & $48 \cdot 3$ & $50 \cdot 8$ & $54 \cdot 3$ & $58 \cdot 6$ & $63 \cdot 8$ & $67 \cdot 8$ \\
9 & 312 & $47 \cdot 9$ & $49 \cdot 3$ & $52 \cdot 0$ & $55 \cdot 7$ & $60 \cdot 3$ & $65 \cdot 8$ & $69 \cdot 9$ \\
10 & 299 & $49 \cdot 2$ & $50 \cdot 8$ & $53 \cdot 8$ & $57 \cdot 7$ & $62 \cdot 6$ & $68 \cdot 1$ & $72 \cdot 1$ \\
11 & 359 & $51 \cdot 1$ & $52 \cdot 8$ & $55 \cdot 9$ & $60 \cdot 1$ & $65 \cdot 1$ & $70 \cdot 6$ & $74 \cdot 6$ \\
12 & 351 & $53 \cdot 3$ & $55 \cdot 1$ & $58 \cdot 4$ & $62 \cdot 6$ & $67 \cdot 7$ & $73 \cdot 3$ & $77 \cdot 1$ \\
13 & 433 & $55 \cdot 7$ & $57 \cdot 5$ & $60 \cdot 8$ & $65 \cdot 1$ & $70 \cdot 2$ & $75 \cdot 7$ & $79 \cdot 4$ \\
14 & 336 & $57 \cdot 9$ & $59 \cdot 7$ & $62 \cdot 9$ & $67 \cdot 1$ & $72 \cdot 1$ & $77 \cdot 5$ & $81 \cdot 2$ \\
15 & 313 & $59 \cdot 2$ & $60 \cdot 8$ & $63 \cdot 9$ & $67 \cdot 9$ & $72 \cdot 7$ & $78 \cdot 0$ & $81 \cdot 6$ \\
16 & 284 & $59 \cdot 5$ & $61 \cdot 1$ & $64 \cdot 0$ & $67 \cdot 8$ & $72 \cdot 4$ & $77 \cdot 3$ & $80 \cdot 8$ \\
17 & 113 & $59 \cdot 7$ & $61 \cdot 2$ & $63 \cdot 9$ & $67 \cdot 5$ & $71 \cdot 8$ & $76 \cdot 4$ & $79 \cdot 8$ \\
& & & & & & & & \\
& & & & & & &
\end{tabular}

${ }^{*}$ Age is in whole years, e.g. 5 years $=5-5.99$ years.

that $\sim 95 \%$ of Hong Kong residents are ethnic Chinese, with no differentiation between Chinese ethnicities ${ }^{(23)}$. Anthropometric differences in children of different Chinese ethnicities have been demonstrated ${ }^{(14)}$. Measurement error or sample bias is unlikely; both studies used the same technique to measure WC and the participants in both studies are representative of the population studied.

Similar to findings in a study on Australian children ${ }^{(24)}$, WC identified a greater number of children and adolescents as having excess central adiposity compared with being classified as overweight or obese using BMI criteria. These results are concerning and have public health implications. Excessive accumulation of central adipose tissue has been associated with cardiovascular risk factors $^{(4,5)}$. Of particular concern was the high proportion (44\%) of young boys with increased WC. While the explanation for the difference between younger and older children is not clear, we speculate that it may represent the advancing wave of the obesity epidemic for boys in China.

We also described the association between age and WHtR in Han children and adolescents. In some populations WHtR has been shown to more readily identify adolescents with adverse cardiovascular risk factors compared with WC and $\mathrm{BMI}^{(6,25-27)}$. The WHtR is also easy to calculate and is considered to be independent of age and sex. However, in our study population we observed a clinical and statistically significant sex difference in WHtR in young children (5-11 years). A similar trend was observed in children living in Hong Kong ${ }^{(28)}$.
Table 3 Waist-to-height ratio percentiles for boys and girls

\begin{tabular}{crlllllll}
\hline Age (years) & \multicolumn{1}{c}{$n$} & 5 th & 10th & 25th & 50th & 75 th & 90 th & 95 th \\
\hline Boys & & & & & & & & \\
5 & 96 & 0.39 & 0.40 & 0.42 & 0.45 & 0.48 & 0.51 & 0.54 \\
6 & 217 & 0.39 & 0.40 & 0.42 & 0.44 & 0.48 & 0.51 & 0.54 \\
7 & 231 & 0.38 & 0.39 & 0.41 & 0.44 & 0.48 & 0.51 & 0.54 \\
8 & 311 & 0.38 & 0.39 & 0.41 & 0.44 & 0.47 & 0.51 & 0.54 \\
9 & 342 & 0.38 & 0.39 & 0.41 & 0.44 & 0.47 & 0.51 & 0.54 \\
10 & 328 & 0.37 & 0.38 & 0.40 & 0.43 & 0.47 & 0.51 & 0.54 \\
11 & 347 & 0.36 & 0.37 & 0.40 & 0.42 & 0.46 & 0.50 & 0.54 \\
12 & 353 & 0.36 & 0.37 & 0.39 & 0.42 & 0.46 & 0.50 & 0.53 \\
13 & 352 & 0.36 & 0.37 & 0.39 & 0.42 & 0.45 & 0.50 & 0.53 \\
14 & 274 & 0.36 & 0.37 & 0.39 & 0.42 & 0.45 & 0.50 & 0.53 \\
15 & 295 & 0.36 & 0.37 & 0.39 & 0.42 & 0.46 & 0.50 & 0.53 \\
16 & 319 & 0.36 & 0.37 & 0.39 & 0.42 & 0.45 & 0.50 & 0.53 \\
17 & 136 & 0.36 & 0.37 & 0.39 & 0.42 & 0.45 & 0.49 & 0.52 \\
Girls & & & & & & & & \\
5 & 147 & 0.36 & 0.38 & 0.40 & 0.43 & 0.46 & 0.49 & 0.50 \\
6 & 226 & 0.36 & 0.37 & 0.40 & 0.43 & 0.46 & 0.48 & 0.50 \\
7 & 254 & 0.35 & 0.37 & 0.39 & 0.42 & 0.45 & 0.48 & 0.49 \\
8 & 296 & 0.35 & 0.37 & 0.39 & 0.42 & 0.45 & 0.47 & 0.49 \\
9 & 312 & 0.35 & 0.36 & 0.39 & 0.42 & 0.44 & 0.47 & 0.48 \\
10 & 299 & 0.35 & 0.36 & 0.39 & 0.41 & 0.44 & 0.47 & 0.48 \\
11 & 359 & 0.35 & 0.36 & 0.39 & 0.41 & 0.44 & 0.47 & 0.48 \\
12 & 351 & 0.35 & 0.36 & 0.39 & 0.42 & 0.45 & 0.47 & 0.49 \\
13 & 433 & 0.35 & 0.37 & 0.39 & 0.42 & 0.45 & 0.48 & 0.49 \\
14 & 336 & 0.36 & 0.37 & 0.40 & 0.43 & 0.46 & 0.48 & 0.50 \\
15 & 313 & 0.36 & 0.37 & 0.40 & 0.43 & 0.46 & 0.48 & 0.50 \\
16 & 284 & 0.36 & 0.37 & 0.40 & 0.43 & 0.46 & 0.49 & 0.50 \\
17 & 113 & 0.36 & 0.38 & 0.40 & 0.43 & 0.46 & 0.49 & 0.50
\end{tabular}

${ }^{*}$ Age is in whole years. e.g. 5 years $=5-5.99$ years.

Table 4 Waist circumference $(\mathrm{cm})$ corresponding to the 90th percentile from three different populations

\begin{tabular}{|c|c|c|c|}
\hline $\begin{array}{l}\text { Age } \\
\text { (years) }\end{array}$ & $\begin{array}{l}\text { Han living in } \\
\text { Chongqing }\end{array}$ & $\begin{array}{l}\text { Han living in } \\
\text { Xingjiang Uyger } \\
\text { Autonomous } \\
\text { Region }^{(14)}\end{array}$ & $\begin{array}{l}\text { Ethnic Chinese } \\
\quad \text { living in } \\
\text { Hong Kong }{ }^{(13)}\end{array}$ \\
\hline \multicolumn{4}{|l|}{ Boys } \\
\hline 5 & 63.5 & & \\
\hline 6 & $65 \cdot 8$ & & $63 \cdot 4$ \\
\hline 7 & $67 \cdot 9$ & 65.5 & 65.0 \\
\hline 8 & $69 \cdot 7$ & $67 \cdot 4$ & $66 \cdot 6$ \\
\hline 9 & $72 \cdot 0$ & $70 \cdot 2$ & $68 \cdot 5$ \\
\hline 10 & $74 \cdot 6$ & $73 \cdot 1$ & $70 \cdot 6$ \\
\hline 11 & $77 \cdot 0$ & $75 \cdot 8$ & $72 \cdot 5$ \\
\hline 12 & $79 \cdot 1$ & $78 \cdot 3$ & $74 \cdot 0$ \\
\hline 13 & $81 \cdot 2$ & $80 \cdot 4$ & $75 \cdot 3$ \\
\hline 14 & $84 \cdot 0$ & $82 \cdot 3$ & $76 \cdot 8$ \\
\hline 15 & $85 \cdot 3$ & 83.9 & $78 \cdot 3$ \\
\hline 16 & $85 \cdot 4$ & $85 \cdot 5$ & $79 \cdot 6$ \\
\hline 17 & 84.9 & $87 \cdot 0$ & $80 \cdot 7$ \\
\hline \multicolumn{4}{|l|}{ Girls } \\
\hline 5 & $58 \cdot 8$ & & \\
\hline 6 & $60 \cdot 2$ & & $58 \cdot 4$ \\
\hline 7 & $62 \cdot 0$ & $60 \cdot 7$ & $60 \cdot 0$ \\
\hline 8 & $63 \cdot 8$ & $62 \cdot 1$ & $61 \cdot 6$ \\
\hline 9 & $65 \cdot 8$ & $63 \cdot 8$ & $63 \cdot 4$ \\
\hline 10 & $68 \cdot 1$ & $66 \cdot 0$ & $65 \cdot 1$ \\
\hline 11 & $70 \cdot 6$ & 68.5 & 66.9 \\
\hline 12 & $73 \cdot 3$ & $71 \cdot 4$ & $68 \cdot 4$ \\
\hline 13 & $75 \cdot 7$ & $74 \cdot 4$ & $69 \cdot 7$ \\
\hline 14 & $77 \cdot 5$ & $76 \cdot 7$ & $70 \cdot 6$ \\
\hline 15 & $78 \cdot 0$ & $77 \cdot 9$ & $71 \cdot 3$ \\
\hline 16 & $77 \cdot 3$ & 78.0 & $71 \cdot 8$ \\
\hline 17 & $76 \cdot 4$ & $77 \cdot 3$ & $72 \cdot 2$ \\
\hline
\end{tabular}


WHtR sex differences are likely to be a result of the differences in overall adiposity; 30\% of boys aged 5-11 years were overweight or obese compared with 19\% for girls.

To date, no cut-points for WHtR have been validated against metabolic outcomes for Han Chinese children and adolescents. In the absence of metabolic markers we defined excess central adiposity as a WHtR $\geq 0 \cdot 5$. Fewer children were identified as having excess central adiposity using a WHtR $\geq 0.5$ compared with WC cut-points, $10 \cdot 2 \%$ and $30 \cdot 0 \%$, respectively. Almost all students (99.5\%) with a WHtR $\geq 0.5$ were identified as having excess central adiposity defined by WC cut-points. We speculate that a WHtR cut-point of 0.5 may identify those children at greatest metabolic risk. However, a limitation of our study is that metabolic markers were not measured and further studies are required to further investigate the use of both the WC cut-points and WHtR in predicting cardiovascular risk in Han Chinese children.

In conclusion, we have constructed WC and WHtR percentile curves for Han Chinese children and adolescents aged 5-17 years living in Chongqing. Our measurements were based on a student population with a relatively high rate of overweight and obesity. Using IOTF criteria $\sim 1$ in 4 boys and 1 in 6 girls were overweight or obese. These data will provide a point of reference for future studies measuring the prevalence of overweight and obesity in China.

\section{Acknowledgements}

This research received no specific grant from any funding agency in the public, commercial or not-for-profit sectors. The authors thank members of Students' Health and Fitness Department of Chongqing Education Committee for supporting this study. The authors would also thank the trained health technicians from the School Students Health Examination Centre in Chongqing YuZhong district and ShaPingBa district for measuring the children. S.P.G. is supported by a NHMRC Australian Clinical Research Fellowship no. 457225. F.X. participated in all aspects of the study, including design, ethics submission, recruiting, data analysis and interpretation, and preparation of the paper. S.P.G. and C.T.C. participated in the concept, data analysis and interpretation, and preparation of the paper. C.B. assisted with data analysis, interpretation and preparation of the paper. Y.Z., C.-L.L., Q.W. and D.-G.W. supervised the study implementation including recruitment, anthropometric measurements and reviewed the paper. Y.-H.L. and S.-Q.L. participated in recruitment, anthropometric measurements and data management. There is no conflict of evidence to disclose.

\section{References}

1. Ji CY (2007) Report on childhood obesity in China (4) prevalence and trends of overweight and obesity in
Chinese urban school-age children and adolescents, 1985-2000. Biomed Environ Sci 20, 1-10.

2. Xu YQ \& Ji CY (2008) Prevalence of the metabolic syndrome in secondary school adolescents in Beijing, China. Acta Paediatr 97, 348-353.

3. Zimmet P, Alberti KG, Kaufman F et al. (2007) The metabolic syndrome in children and adolescents - an IDF consensus report. Pediatr Diabetes 8, 299-306.

4. Freedman DS, Serdula MK, Srinivasan SR et al. (1999) Relation of circumferences and skinfold thicknesses to lipid and insulin concentrations in children and adolescents: the Bogalusa Heart Study. Am J Clin Nutr 69, 308-317.

5. Garnett SP, Baur LA \& Cowell CT (2008) Waist-to-height ratio: a simple option for determining excess central adiposity in young people. Int J Obes (Lond) 32, 1028-1030.

6. Savva SC, Tornaritis M, Savva ME et al. (2000) Waist circumference and waist-to-height ratio are better predictors of cardiovascular disease risk factors in children than body mass index. Int $J$ Obes Relat Metab Disord 24, $1453-1458$.

7. Fernandez JR, Redden DT, Pietrobelli A et al. (2004) Waist circumference percentiles in nationally representative samples of African-American, European-American, and Mexican-American children and adolescents. J Pediatr 145, 439-444.

8. Misra A, Wasir JS \& Vikram NK (2005) Waist circumference criteria for the diagnosis of abdominal obesity are not applicable uniformly to all populations and ethnic groups. Nutrition 21, 969-976.

9. Zhu S, Heymsfield SB, Toyoshima $\mathrm{H}$ et al. (2005) Raceethnicity-specific waist circumference cutoffs for identifying cardiovascular disease risk factors. Am J Clin Nutr 81, 409-415.

10. McCarthy HD, Jarrett KV \& Crawley HF (2001) The development of waist circumference percentiles in British children aged 5.0-16.9 y. Eur J Clin Nutr 55, 902-907.

11. World Health Organization Western Pacific Region, International Association for the Study of Obesity \& International Obesity Task Force (2000) The Asia-Pacific Perspective: Redefining Obesity and Its Treatment. Sydney: Health Communications Australia Pty Limited.

12. Eisenmann JC (2005) Waist circumference percentiles for 7- to 15-year-old Australian children. Acta Paediatr 94, $1182-1185$.

13. Sung RY, So HK, Choi KC et al. (2008) Waist circumference and waist-to-height ratio of Hong Kong Chinese children. BMC Public Health 8, 324.

14. Yan W, Yao H, Dai J et al. (2008) Waist circumference cutoff points in school-aged Chinese Han and Uygur children. Obesity (Silver Spring) 16, 1687-1692.

15. McCarthy HD \& Ashwell M (2006) A study of central fatness using waist-to-height ratios in UK children and adolescents over two decades supports the simple message - 'keep your waist circumference to less than half your height'. Int $J$ Obes (Lond) 30, 988-992.

16. Cole TJ, Bellizzi MC, Flegal KM et al. (2000) Establishing a standard definition for child overweight and obesity worldwide: international survey. BMJ 320, 1240-1243.

17. Ji CY (2005) Report on childhood obesity in China (1) body mass index reference for screening overweight and obesity in Chinese school-age children. Biomed Environ Sci 18, 390-400.

18. Sung RY, So HK, Choi KC et al. (2007) Waist circumference and body mass index in Chinese children: cutoff values for predicting cardiovascular risk factors. Int J Obes (Lond) $\mathbf{3 1}$, $550-558$.

19. Ng VW, Kong AP, Choi KC et al. (2007) BMI and waist circumference in predicting cardiovascular risk factor clustering in Chinese adolescents. Obesity (Silver Spring) 15, 494-503. 
20. Cole TJ (1990) The LMS method for constructing normalised growth standards. Eur J Clin Nutr 44, 45-60.

21. Medical Research Council, UK (1997-2005) LMS ChartMaker Light. http://www.healthforallchildren.co.uk (accessed September 2008)

22. Wu Y (2006) Overweight and obesity in China. BMJ 333, 362-363.

23. IndexMundi (2008) Hong Kong Chinese ethnicities. http:// indexmundi.com/hong_kong/ethnic_groups.html (accessed September 2008).

24. Garnett SP, Cowell CT, Baur LA et al. (2005) Increasing central adiposity: the Nepean longitudinal study of young people aged 7-8 to 12-13 y. Int J Obes (Lond) 29, 1353-1360.
25. Hara M, Saitou E, Iwata F et al. (2002) Waist-to-height ratio is the best predictor of cardiovascular disease risk factors in Japanese schoolchildren. J Atheroscler Thromb 9 , 127-132.

26. Maffeis C, Banzato C \& Talamini G (2008) Waist-to-height ratio, a useful index to identify high metabolic risk in overweight children. J Pediatr 152, 207-213.

27. Kahn HS, Imperatore G \& Cheng YJ (2005) A populationbased comparison of BMI percentiles and waist-to-height ratio for identifying cardiovascular risk in youth. $J$ Pediatr 146, 482-488.

28. So HK, Nelson EA, Li AM et al. (2008) Secular changes in height, weight and body mass index in Hong Kong Children. BMC Public Health 8, 320. 